\title{
Catheter Working Length
}

National Cancer Institute

\section{Source}

National Cancer Institute. Catheter Working Length. NCI Thesaurus. Code C150186.

The length of the catheter that can be inserted into the body or the working/functional measurement from the beginning to the end of delivery system. 